\title{
Mean Platelet Volume as an Early Predictor for The Complication of Coronavirus Disease 19
}



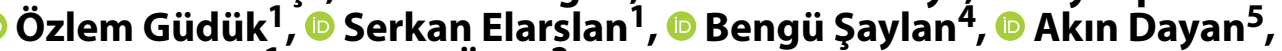 \\ Yaşar Sertbaş ${ }^{1}$, (i) Kamil Özdil ${ }^{2}$
}

${ }^{1}$ Department of Internal Medicine, University of Health Sciences Turkey, Fatih Sultan Mehmet Training and Research Hospital, Istanbul, Turkey ${ }^{2}$ Department of Internal Medicine, University of Health Sciences Turkey, Umraniye Training and Research Hospital, Istanbul, Turkey ${ }^{3}$ Department of Cardiology, University of Health Sciences Turkey, Siyami Ersek Training and Research Hospital, Istanbul, Turkey ${ }^{4}$ Department of Pulmonology, University of Health Sciences Turkey, Sultan II. Abdulhamid Han Training and Research Hospital, Istanbul, Turkey ${ }^{5}$ Department of Family Medicine, University of Health Sciences Turkey, Hamidiye Faculty of Medicine, Haydarpaşa Numune Health Application and Research Center, Istanbul, Turkey

\begin{abstract}
Introduction: Although several studies have been conducted on the association of mean platelet volume (MPV) with the diagnosis, morbidity, and mortality of coronavirus disease 19 (COVID-19) patients, the results were contradictory. We aimed to investigate the effects of MPV on hospitalization and mortality with a significant number of patients.

Methods: This multicenter study was carried out retrospectively on 9.487 patients. The demographic information and laboratory parameters of the patients were obtained from their medical records in the hospital. Analyses were performed using Statistical Package for the Social Sciences (SPSS) version 22.0 for Windows.

Results: In total, there were 806 intensive care unit (ICU) patients, in addition to 8.681 non-ICU patients. The mean age of

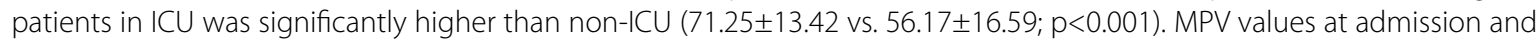
max MPV values during the period of hospitalization were significantly higher in patients followed in the ICU $(p<0.05)$. MPVfirst' $M^{\prime} V_{\text {last' }} \triangle M P V_{\text {last-first' }}$ and $\triangle M P V \%$ values were significantly higher in non-survivor group than the survived patients. As a result of receiver-operating characteristic analysis, the risk of mortality was determined to be 5.15 fold greater in people with MPVlast $\geq 10.05$ fl. (ODDS ratio:5.15 95\% Cl: 4.374-6.067). The patient has a 4.62 fold risk of death after a $2.18 \%$ increase of arrival MPV value (ODDS ratio: 4.62, 95\% Cl: 3.455-6.203).

Discussion and Conclusion: We thought that MPV and MPV changes during hospitalization may be a powerful predictor of mortality in patients with COVID-19.

Keywords: Coronavirus disease 19; hospital stay; mean platelet volume; mortality.
\end{abstract}

$\mathrm{O}$ December 2019, coronavirus disease 19 (COVID-19) caused by severe acute respiratory syndrome coronavirus 2 (SARS-CoV-2) virus was first reported in Wuhan, China $^{[1]}$. In March 2020, the World Health Organization
(WHO) declared COVID-19 as pandemic disease and since then, COVID-19 has spread rapidly across the world with 123.216.178 confirmed cases and 2.714.517 deaths until February 23, 2021 ${ }^{[2]}$. Pneumonia remains the leading

Correspondence (İletişim): Yaşar Sertbaş, M.D. Saglik Bilimleri Universitesi Fatih Sultan Mehmet Egitim ve Arastirma Hastanesi, Istanbul, Turkey Phone (Telefon): +90 2165787840 E-mail (E-posta): yserzincan24@gmail.com 
cause of death in critical care patients, despite the implementation of several strategies over the last few decades that have aimed to optimize outcomes for patients with pneumonia ${ }^{[3-5]}$. Early recognition and risk stratification are necessary to improve outcomes for pneumonia patients ${ }^{[6]}$.

Easily accessible, inexpensive, and widely used laboratory tests that show the severity of COVID-19 are important. In addition to their main role in hemostasis and thrombosis, platelets are thought to play a role in inflammation and immune responses ${ }^{[7]}$. Mean platelet volume (MPV) is an indicator of platelet size and activity. Several studies have reported that MPV changes are associated with morbidity and mortality in patients with diseases such as sepsis, diabetes mellitus, myocardial infarction, and chronic inflammatory disorders ${ }^{[8-11]}$. Although there are several studies about the association of MPV with the diagnosis, morbidity, and mortality of COVID-19 patients, the results were contradictory ${ }^{[11-14]}$. Since we thought that these conflicting results seen in previous studies were due to their small number of patient groups or their study design, we aimed to investigate the effects of MPV on hospitalization and mortality with a large patient population.

\section{Materials and Methods}

\section{Sample Collection}

This multicenter study was carried out retrospectively on 9.487 patients (over 18 years old) who were hospitalized with the diagnosis of COVID-19 in four hospitals of Istanbul between March 15, 2020, and December 15, 2020. All these patients had COVID-19 diagnosis by the RNA test through polymerase chain reaction and/or by the computed tomography imaging. The demographic information and laboratory parameters of the patients were obtained from their medical records in the hospital. MPV values of patients were recorded from laboratory findings. Patients' values at admission were defined as $\mathrm{MPV}_{\text {first' }}$ the peak values during hospitalization MPVmax and final values as $\mathrm{MPV}_{\text {last }}$. Peak laboratory values were recorded for C-reactive protein, erythrocyte sedimentation rate, white blood cell count, procalcitonin, and D-dimer as inflammatory markers with other biochemical markers such as aspartate aminotransferase, alanine aminotransferase, creatinine, and hemogram, as organ-specific parameters for liver, kidney, and bone marrow. The The Turkish health ministry and local ethical committee approval were obtained from an Fatih Sultan Mehmet Training and Research Hospital (FSMEAH-KAEK 2020/126). The Helsinki Declaration of Human Rights was followed.

\section{Statistical Analysis}

Analyses were performed using Statistical Package for the Social Sciences (SPSS) version 22.0 for Windows. The results of all parameters belonging to patients were given as mean \pm standard deviation and median (interquartile range Student's t-test was used to compare normally distributed parameters between two groups, and Mann-Whitney $U$ test was used for comparisons of parameters not showing normal distribution between two groups). In the determination of cut-off points for MPV receiver-operating characteristic (ROC) analysis was used, bivariate correlation analyses were performed using the Pearson correlation test. Categorical variables were analyzed by the $x^{2}$ test. Probability values were two-tailed and a $p<0.05$ was considered significant.

\section{Results}

In total, 9.487 COVID-19 patients were recruited to this study. Among these patients, 4.358 (46\%) of them were female and $5.129(54 \%)$ of the participants were male with a total mean age of $57.45 \pm 16.88$. To compare the severity of the disease and MPV values, we separated the patients into two groups: Group 1, those who were followed up in the intensive care unit (ICU) and Group 2, those who did not need to be followed in ICU. In total, there were 806 ICU patients (Group 1) in addition to 8.681 service patients (Group 2). The mean age of patients in Group 1 was significantly higher than Group 2 (71.25 \pm 13.42 vs. $56.17 \pm 16.59 ; p<0.001)$. Among the patients hospitalized with a diagnosis of COVID-19, the MPV values at admission $\left(M V_{\text {first }}\right)$ and max MPV values (MPVmax) during the period of hospitalization were significantly higher in patients followed in the ICU (Table 1).

Other than hospitalization to ICU, we also evaluate the mortality of COVID-19 patients. The age of the patient who died due to COVID-19 was significantly higher than sur-

Table 1. Comparison of MPV values of patients due to their hospitalization in ICU

\begin{tabular}{|c|c|c|c|}
\hline & $\begin{array}{c}{ }^{*} \text { Group } 1 \\
(n=806)\end{array}$ & $\begin{array}{c}* * \text { Group } 2 \\
(n=8681)\end{array}$ & \\
\hline \multicolumn{4}{|l|}{$M P V_{\text {first }}$} \\
\hline Mean \pm SD & $9.62 \pm 1.08$ & $9.48 \pm 1.03$ & $<0.001$ \\
\hline Median (IQR) & $9.5(8.8-10.2)$ & $9.4(8.8-10.1)$ & \\
\hline \multicolumn{4}{|l|}{$\mathrm{MPV}_{\max }$} \\
\hline Mean $\pm S D$ & $11.18 \pm 1.47$ & $10.12 \pm 1.12$ & $<0.001$ \\
\hline Median (IQR) & $11(10.1-11.9)$ & $10(9.3-10.9)$ & \\
\hline
\end{tabular}

*Group 1: Patients followed on ICU; **Group 2: Patients followed on nonintensive care unit; ICU: Intensive care unit; MPV: Mean platelet volume. 
vived ones $(72.64 \pm 12.5$ vs. $56.17 \pm 16.57 ; p<0.001)$. Table 2 shows the association between the MPV values and mortality of the patients. Both the initial and final MPV values of the patients were significantly higher in the non-survivor group than the survived patients. As it is seen on the table, the ratio of the difference ( $\triangle \mathrm{MPV} \%$ ) or just the difference between the first and last MPV values $\left(\triangle M P V_{\text {last-first }}\right)$ was also greater on the non-survivor group of the patients $(p<0.001)$. When we compared the difference between the $M_{P V}$ first and MPV $_{\text {last }}$ for survived $(9.48 \pm 1.01$ vs. $10.14 \pm 1.25 ; \mathrm{p}<0.001)$ and non-survived groups $(9.61 \pm 1.06$ vs. $11.42 \pm 1.51 ; p<0.001)$, we have seen that there was a significant increase of initial MPV values during hospitalization for each group.

When the ROC analysis used for the evaluation of MPV parameters, it was clear that $M P V_{\text {last }}$ was the most significant parameter (Table 3). MPV values higher than 10.05 were suggested to be a valuable parameter for predicting the mortality of the patients (Fig. 1). Other than the analysis mentioned above, ROC analysis also showed that an increase in MPV of 0.2 (2.18\%) was seems to be other predic-

Table 2. Comparison of MPV values of coronavirus disease 2019 survivors and non-survivors

\begin{tabular}{|c|c|c|c|}
\hline & $\begin{array}{l}\text { Survived } \\
(\mathrm{n}=\mathbf{8 . 7 5 2})\end{array}$ & $\begin{array}{c}\text { Non-survived } \\
\quad(n=735)\end{array}$ & \\
\hline \multicolumn{4}{|l|}{$M P V_{\text {first }}$} \\
\hline Mean \pm SD & $9.48 \pm 1.01$ & $9.61 \pm 1.06$ & $<0.001$ \\
\hline Median (IQR) & $9.4(8.8-10.1)$ & $9.4(8.9-10.2)$ & \\
\hline \multicolumn{4}{|l|}{$\mathrm{MPV}_{\text {last }}$} \\
\hline Mean \pm SD & $10.14 \pm 1.25$ & $11.42 \pm 1.51$ & $<0.001$ \\
\hline Median (IQR) & $10(9.3-10.9)$ & $11.2(10.3-1.3)$ & \\
\hline \multicolumn{4}{|l|}{$\Delta \mathrm{MPV}_{\text {last-first }}$} \\
\hline Mean $\pm S D$ & $-0.121 \pm 0.75$ & $0.831 \pm 1.30$ & $<0.001$ \\
\hline Median (IQR) & $-0.1(-0.6-4)$ & $0.7(0-1.5)$ & \\
\hline \multicolumn{4}{|l|}{$\triangle \mathrm{MPV} \%$} \\
\hline Mean $\pm S D$ & $0.97 \pm 7.7$ & $8.91 \pm 13.52$ & $<0.001$ \\
\hline Median (IQR) & $-1.06(-5.9-3.67)$ & $7.06(0-15.99)$ & \\
\hline
\end{tabular}

MPV: Mean platelet volume.

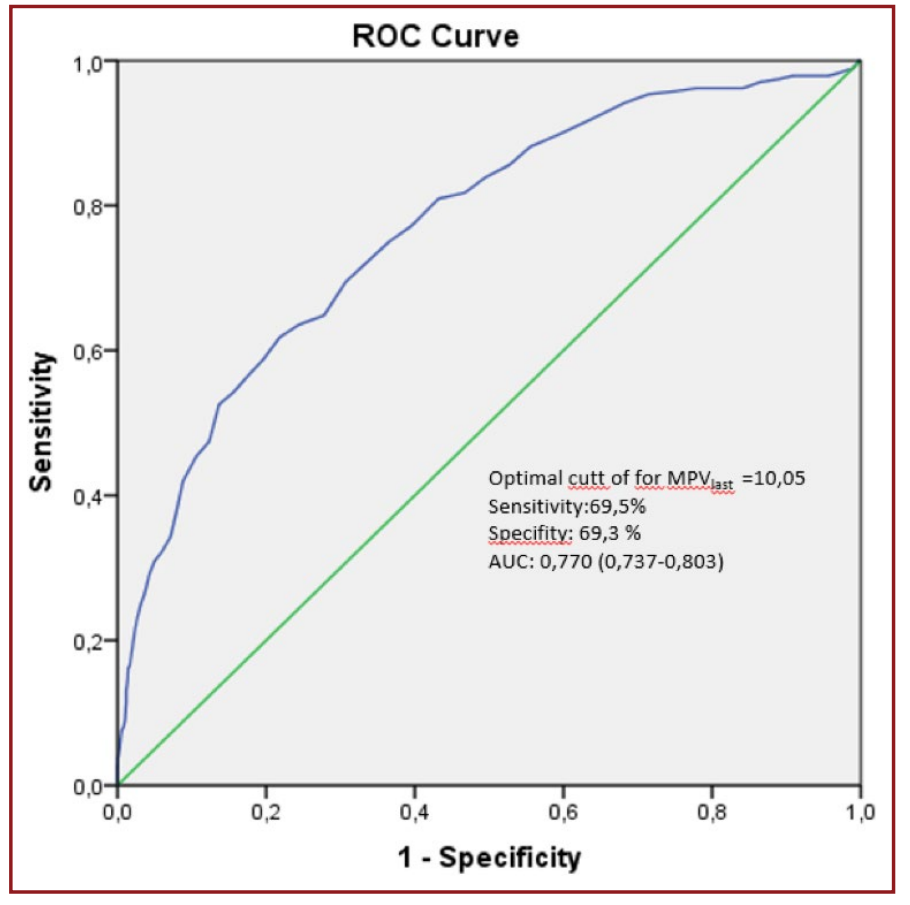

Figure 1. Receiver-operating characteristic curve of MPVlast predicting mortality.

tors of mortality. The risk of mortality was determined to be 5.15 fold greater in people with $\mathrm{MPV}_{\text {last }} \geq 10.05 \mathrm{fl}$. (ODDS ratio: $5.1595 \% \mathrm{Cl}$ : 4.374-6.067). The patient has 4.62 fold risk of death after a $2.18 \%$ increase of arrival MPV value (ODDS ratio: $4.62,95 \% \mathrm{Cl}: 3.455-6.203)$.

\section{Discussion}

This study aimed to investigate the association between the prognosis and MPV values of the COVID-19 patients. Both the initial and max. MPV values were found to be higher on patients followed at ICU. Besides that, we observed that all MPV parameters were higher for the non-survived group than survived ones. To see the cut-off points for MPV parameters, we have done the ROC analysis and see that rather than admission MPV values, last MPV parameters of the patient and increase ratio of MPV values were much valuable than the other parameters.

Table 3. Receiver-operating characteristic analysis of MPV values affecting mortality of the patients

\begin{tabular}{lccccc}
\hline Risk factor & AUC (\%95) & Cut off & P & Sensitivity \% & Specificity \% \\
\hline$M_{\text {first }}$ & $0.587(0.548-0.626)$ & 9.65 & $<0.001$ & 57.6 & 53.9 \\
$M_{\text {last }}$ & $0.770(0.737-0.803)$ & 10.05 & $<0.001$ & 69.5 & 69.3 \\
$\Delta M_{\text {last-first }}$ & $0.742(0.702-0.781)$ & 0.200 & $<0.001$ & 69.1 & 68.0 \\
$\Delta M P V \%$ & $0.739(0.702-0.781)$ & 2.18 & $<0.001$ & 68.3 \\
\hline
\end{tabular}

MPV: Mean platelet volume. 
Although studies have generally been conducted on MPV and mortality rates, two previous studies have focused on the difference between patients hospitalized in intensive care and patients who do not need intensive care, but there was no significant difference. In the study of 37 COVID-19 patients, there was no difference between MPV values at admission among the patients in ICU and service ${ }^{[15]}$. In another study, Asan et al. ${ }^{[16]}$ included 697 patients in their study, and 27 of them were followed up in the ICU. Although the MPV/platelet ratios of the patients followed in the ICU were slightly higher $(p=0.049)$, there was no significant difference between MPV values. In our study, both the MPV at admission and the max MPV values after hospitalization were significantly higher in patients followed in the ICU.

There are significant differences among the studies, which were about the MPV values and mortalities of patients. Depending on the time at which MPV was examined during the period of hospitalization, these studies had been performed in both before and after COVID-19 epidemic. In the studies conducted by Altun et al. ${ }^{[17]}$ and Kucukardali et al., ${ }^{[18]}$ although the arrival MPV values of the patients who died were slightly higher than those living, no statistically significant difference was found. In addition, in their study, Kucukardali et al. ${ }^{[18]}$ were found a significant correlation between MPV and APACHE score $(r=0.34, p<0.05)$ which is a scoring system associated with increased risk of hospital death. In another study with 119 COVID-19 patients, the arrival MPV values did not show any difference between the non-survivor and survivor groups $^{[19]}$. It is observed that almost all of the studies that did not find a significant relationship between MPV values and mortality had been used the MPV values of the first admission to the hospital.

Other than these studies in which MPV values did not show any difference between the survivor and non-survivor patients, in their study with COVID-19 patients, Güçlü et al. found that MPV values were not significant when compared with the severity of the disease. Patients with room air oxygen saturation $<90 \%$ were considered as severe COVID-19. MPV values measured during discharge or just before death were found to be significantly higher in patients grouped as non-survivor. At the same time, the difference between the last MPV and the first arrival MPV values was significantly higher in the non-survivor group. They claimed that 1 unit increase in MPV increased mortality 1.76 times $^{[20]}$. In a study conducted by Lee et al., ${ }^{[21]}$ although no significant difference was found between the mortality and arrival MPV values $(p=0.452)$ of patients, they concluded that $\triangle M P V$ during ICU might be used as a prognostic marker of mortality in ICU patients with pneumoni. In another study with 82 survivors and 25 non-survivors, both the admission MPV and last MPV values were higher on non-survivor group than survivors ${ }^{[22]}$. In the study performed by Gencay et al., ${ }^{[23]}$ while the first and last MPV values were different in the deceased group, there was no significant difference between the first and last MPV values of the discharged patients were found. In our study, in accordance with the above-mentioned studies, it was observed that besides the first and last MPV values, the difference and ratio between them were also associated with mortality.

The pathophysiology of unusually high pathogenicity for SARS-CoV has not been completely understood. Preliminary studies have shown that increased levels of proinflammatory cytokine in the serum were associated with pulmonary inflammation and extensive lung damage in SARS patients ${ }^{[24]}$. In their study, Fu et al. ${ }^{[25]}$ claimed that primary inflammation triggered by rapid viral replication and release of potent proinflammatory cytokines occurs in the early stages of COVID-19 infection. Huang et al. ${ }^{[26]}$ in their study reported that patients with COVID-19 requiring ICU admission had higher levels of interleukins. Besides their effect on inflammation, COVID-19 has been shown to have effects on the hematopoietic system and hemosta$\operatorname{sis}^{[27]}$. Studies pointed out that patients diagnosed with COVID-19 are susceptible to hypercoagulation and thrombotic events ${ }^{[28]}$. Microvascular thrombosis has been observed in post-mortem examinations of the patients ${ }^{[28]}$. As a coagulation parameter, high levels of D-dimer and prolonged prothrombin time have also been detected in COVID-19 patients ${ }^{[29]}$; we thought that, outside of different mechanisms, inflammatory cytokines might stimulate the thrombopoiesis which results a release of large and active platelets that could induce the occurrence of thromboembolism. These changes may explain the increase in MPV values during the hospitalization period with the higher values of MPV and $\triangle M P V \%$ on non-survivors than discharged patients.

As far as we can see, although our study is one of the studies with the highest number of patients investigating the relationship between MPV and COVID-19 in the literature, we believe it has some limitations. One of the limitations is the retrospective nature of the study that could be planned as prospectively. Finally, we did not exclude the chronic diseases that can affect the MPV sizes as diabetes, renal diseases, and hypoxemia. 
In conclusion, we thought that MPV and MPV changes during hospitalization may be a powerful predictor of mortality in patients with COVID-19. We recommend to record and evaluate the MPV changes for the improvement of patients care.

Ethics Committee Approval: The The Turkish health ministry and local ethical committee approval were obtained from an Fatih Sultan Mehmet Training and Research Hospital (FSMEAHKAEK 2020/126). The Helsinki Declaration of Human Rights was followed.

Peer-review: Externally peer-reviewed.

Authorship Contributions: Concept - Y.S., M.S., V.K., S.D., K.Ö., A.D.; Design - Y.S., V.K., S.D., K.Ö., M.S.; Supervision - Y.S., K.Ö.; Resources - Y.S., M.S., V.K., Z.Y., E.E.S., Ö.G.; Materials - V.K., Z.Y., E.E.S., S.E.; Data collection and/or processing - V.K., S.E., Y.S., E.E.S., Z.Y., B.Ş.; Analysis and/or interpretation - Y.S., V.K., S.D., B.Ş., A.D.; Literature review - Y.S., S.E., V.K.; Writing - Y.S., M.S., V.K., K.Ö., S.E.; Critical review - Y.S., K.Ö., V.K., S.D., M.S., Ö.G.

Conflict of Interest: None declared.

Financial Disclosure: The authors declared that this study received no financial support.

\section{References}

1. Gao J, Tian Z, Yang X. Breakthrough: Chloroquine phosphate has shown apparent efficacy in treatment of COVID-19 associated pneumonia in clinical studies. Biosci Trends 2020;14:723. [CrossRef]

2. World Health Organization. Coronavirus Disease 2019 (COVID-19) Weekly Epidemiological Update. Geneva: World Health Organization; 2020. Available at: https://www.who. int/docs/default-source/coronaviruse/situation-reports/ 20200817-weekly-epi-update-1.pdf.

3. Liapikou A, Ferrer M, Polverino E, Balasso V, Esperatti M, Piñer $\mathrm{R}$, et al. Severe community-acquired pneumonia: Validation of the infectious diseases society of America/American thoracic society guidelines to predict an intensive care unit admission. Clin Infect Dis 2009;48:377-85. [CrossRef]

4. Restrepo MI, Mortensen EM, Rello J, Brody J, Anzueto A. Late admission to the ICU in patients with community-acquired pneumonia is associated with higher mortality. Chest 2010;137:552-7. [CrossRef]

5. Restrepo MI, Mortensen EM, Velez JA, Frei C, Anzueto A. A comparative study of community-acquired pneumonia patients admitted to the ward and the ICU. Chest 2008;133:6107. [CrossRef]

6. Pereira JM, Paiva JA, Rello J. Severe sepsis in community-acquired pneumonia--early recognition and treatment. Eur J Intern Med 2012;23:412-9. [CrossRef]

7. Thomas MR, Storey RF. The role of platelets in inflammation. Thromb Haemost 2015;114:449-58. [CrossRef]

8. Venkata C, Kashyap R, Farmer JC, Afessa B. Thrombocytopenia in adult patients with sepsis: Incidence, risk factors, and its association with clinical outcome. J Intensive Care 2013;1:9.

9. Sertbas Y, Sertbas M, Okuroglu N, Ozturk MA, Abacar KY, Ozdemir A. Mean platelet volume changes before and after glycated hemoglobin (HbA1c) improvement in a large study population. Arch Med Sci 2017;13:711-5. [CrossRef]

10. Frossard M, Fuchs I, Leitner JM, Hsieh K, Vlcek M, Losert H, et al. Platelet function predicts myocardial damage in patients with acute myocardial infarction. Circulation 2004;110:1392-7.

11. Korniluk A, Koper-Lenkiewicz OM, Kamińska J, Kemona H, Dymicka-Piekarska V. Mean platelet volume (MPV): New perspectives for an old marker in the course and prognosis of Inflammatory conditions. Mediators Inflamm 2019;2019:9213074. [CrossRef]

12. Gumus $H$, Demir A, Yükkaldıran A. Is mean platelet volume a predictive marker for the diagnosis of COVID-19 in children? Int J Clin Pract 2021;75:e13892. [CrossRef]

13. Zhong Q, Peng J. Mean platelet volume/platelet count ratio predicts severe pneumonia of COVID-19. J Clin Lab Anal 2021;35:e23607. [CrossRef]

14. Ozcelik N, Ozyurt S, Yilmaz Kara B, Gumus A, Sahin U. The value of the platelet count and platelet indices in differentiation of COVID-19 and influenza pneumonia. J Med Virol 2021;93:2221-6. [CrossRef]

15. Aktaş A, Sener K, Yilmaz N, Tunc M, Yolcu S. Is mean platelet volume useful for predicting the prognosis of COVID-19 diagnosed patients? Int J Res Stud Med Health Sci 2020;7:8-11.

16. Asan A, Üstündağ $Y$, Koca N, Şimşek A, Sayan HE, Parildar $H$, et al. Do initial hematologic indices predict the severity of COVID-19 patients? Turk J Med Sci 2021;51:39-44. [CrossRef]

17. Altun Y, Demircan F, Mengeloğlu FZ, Namuslu M. The relationship between mean platelet volume and mortality in patients in intensive care unit. J Clin Exp Invest 2011;2:408-11. [CrossRef]

18. Kucukardali Y, Onem Y, Terekeci H, Tangi F, Sahan B, Erikci AA, et al. Mean platelet volume (MPV) in intensive care unit (ICU) patients: Is it a useful parameter in assessing prediction for mortality? J Med Med Sci 2010;1:61-4.

19. Fois AG, Paliogiannis P, Scano V, Cau S, Babudieri S, Perra R, et al. The systemic Inflammation Index on admission predicts In-hospital mortality in COVID-19 patients. Molecules 2020;25:5725. [CrossRef]

20. Güçlü E, Kocayiğit H, Okan HD, Erkorkmaz U, Yürümez Y, Yaylacı S, et al. Effect of COVID-19 on platelet count and its indices. Rev Assoc Med Bras 2020;66:1122-7. [CrossRef]

21. Lee JH, Park M, Han S, Hwang JJ, Park SH, Park SY. An increase in mean platelet volume during admission can predict the prognoses of patients with pneumonia in the intensive care unit: A retrospective study. PLoS One 2018;13:e0208715.

22. Ouyang SM, Zhu HQ, Xie YN, Zou ZS, Zuo HM, Rao YW, et al. Temporal changes in laboratory markers of survivors and non-survivors of adult inpatients with COVID-19. BMC Infect Dis 2020;20:952. [CrossRef]

23. Gencay I, Büyükkoçak Ü, Ateş G, Caglayan O. Mean platelet volume and platelet distribution width predictors in tenten- 
sive care unit. J Health Sci 2020;3:51-5. [CrossRef]

24. Wong CK, Lam CW, Wu AK, Ip WK, Lee NL, Chan IH, et al. Plasma inflammatory cytokines and chemokines in severe acute respiratory syndrome. Clin Exp Immunol 2004;136:95-103.

25. Fu Y, Cheng Y, Wu Y. Understanding SARS-CoV-2-mediated Inflammatory responses: From mechanisms to potential therapeutic tools. Virol Sin 2020;35:266-71. [CrossRef]

26. Huang C, Wang Y, Li X, Ren L, Zhao J, Hu Y, et al. Clinical features of patients infected with 2019 novel coronavirus in Wuhan, China. Lancet 2020;395:497-506. [CrossRef]

27. Magro C, Mulvey JJ, Berlin D, Nuovo G, Salvatore S, Harp J, et al. Complement associated microvascular injury and thrombosis in the pathogenesis of severe COVID-19 infection: A report of five cases. Transl Res 2020;220:1-3. [CrossRef]

28. Bikdeli B, Madhavan MV, Jimenez D, Chuich T, Dreyfus I, Driggin $\mathrm{E}$, et al. COVID-19 and thrombotic or thromboembolic disease: Implications for prevention, antithrombotic therapy, and follow-up: JACC state-of-the-art review. J Am Coll Cardiol 2020;75:2950-73. [CrossRef]

29. Noris P, Melazzini F, Balduini CL. New roles for mean platelet volume measurement in the clinical practice? Platelets 2016;27:607-12. [CrossRef] 